\title{
Multiple Esophageal Papillomas: A Unique Image
}

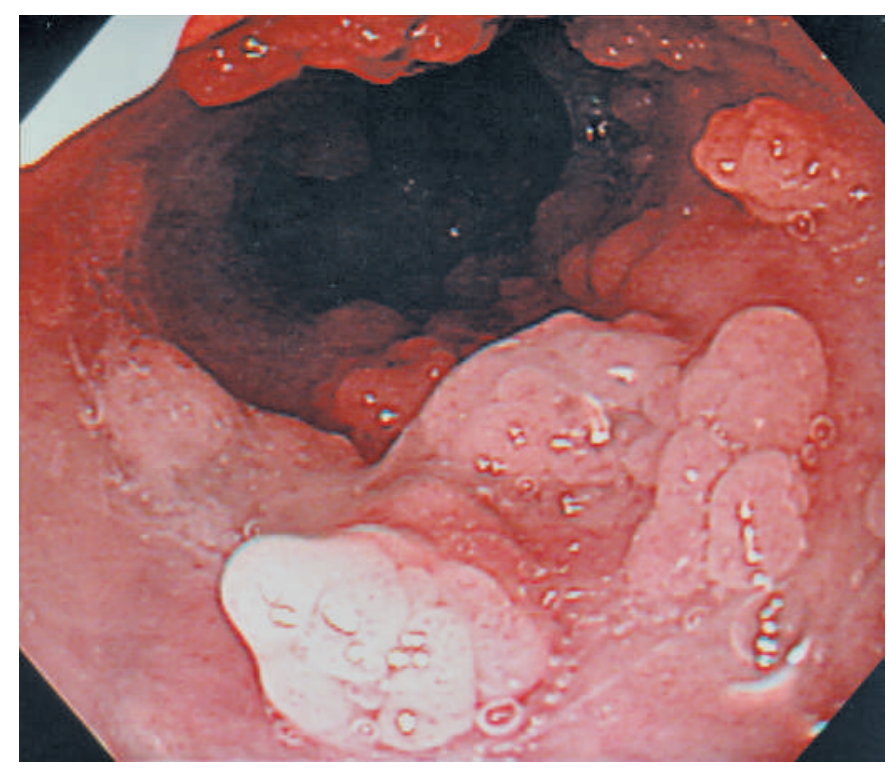

Figure 1 A 91-yearold woman presented to the emergency department of our hospital with a main complaint of hematemesis and tarry stools. An emergency upper endoscopy revealed multiple gastric ulcers, which were diagnosed as the source of bleeding. From the upper thoracic esophagus to the gastroesophageal junction, clustered, papillary, whitish, semipedunculated lesions, $5-10 \mathrm{~mm}$ in size, were seen.

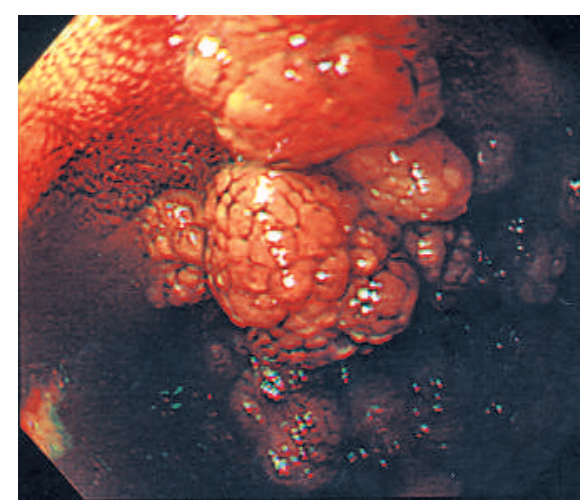

Figure 2 lodine spraying demonstrated that these elevated lesions stained lightly, and possessed a granular surface.

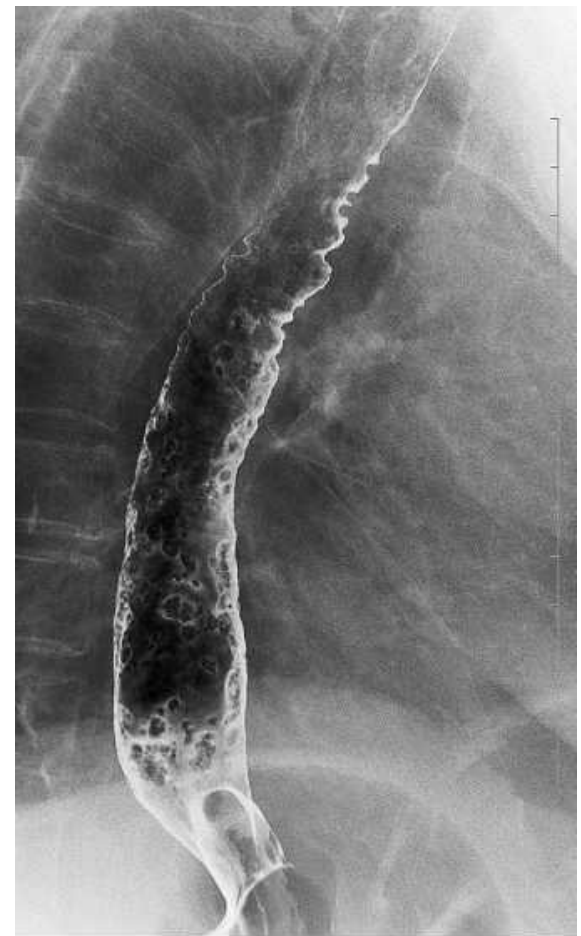

Figure 3 Radiographic examination showed multiple, small, elevated lesions throughout the thoracic esophagus.

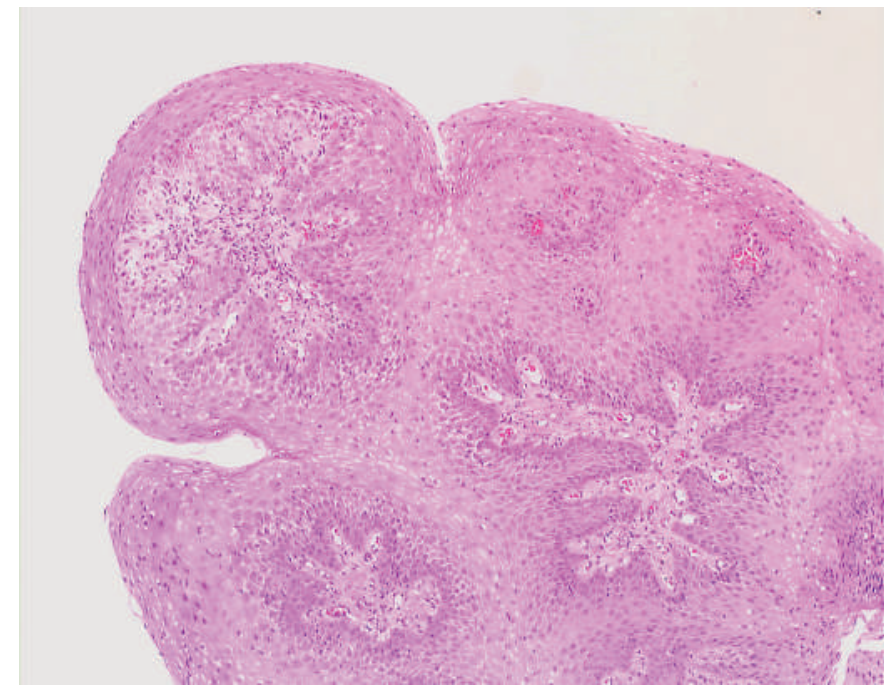

Figure 4 Endoscopic biopsy revealed papillomatous proliferation of mature acanthotic squamous epithelium arranged along branched fibrovascular stalks. The final pathological diagnosis was squamous papilloma. Testing for human papillomavirus infection was negative.

Corresponding Author

S. Tanaka', M. Goubaru', T. Ohta', M. Ogata', I. Murakami' ${ }^{2}$

${ }^{1}$ Department of Gastroenterology, National Hospital Organization Iwakuni Clinical Center, Iwakuni, Japan

2 Department of Pathology, National Hospital Organization Iwakuni Clinical Center, Iwakuni, Japan

\section{S. Tanaka, M.D.}

Department of Gastroenterology National Hospital Organization Iwakuni Clinical Center 2-5-1 Kuroiso-cho Iwakuni 740-0041, Japan Fax: $\quad+81-827-31-7059$

E-mail: tanaka@iwakuni-nh.go.jp 